\title{
What do managers look for in candidates for international assignments?
}

\section{Yener Kandogan}

School of Management, University of Michigan-Flint

Correspondence

Yener Kandogan, University of Michigan-Flint School of Management, University of Michigan, Center for Russian, East-European and Eurasian Studies, 303 E. Kearsley, Flint, MI 48503.

Email: yener@umich.edu
Globalization of business highlights the need for individuals with the right skills and experiences for international assignments. Gender, age, ethnicity, family situation, professional qualifications, past international experiences, as well as psychological characteristics can be counted among the selection criteria of a candidate for such assignments. This current study examines the role of assignment context and selecting manager characteristics in the selection process. First, these candidate characteristics are considered together with features of the assignment such as duration, destination, and task performed to examine if their consistency are critical. Second, whether managers draw from their own past and consider their own family situation and international experiences, or select a candidate with same gender, age, or ethnicity is investigated. The findings suggest that without matching manager characteristics and assignment features, candidate characteristics are of little importance.

\section{KEYWORDS}

assignment types, supervisor-subordinate relationship, contingency theory, homophily

\section{1 | INTRODUCTION}

According to Global Relocation Trends survey (2014), 47\% of companies reported an increased number of international assignees in 2013 over the previous year, and $40 \%$ had expected further increases. Additionally, the percentage of assignments unrelated to headquarters increased over the years, with $46 \%$ in 2012 . This figure was $37 \%$ in 2005. The need for business professionals with necessary skills and experiences for international assignments is clearly critical for an increasing number of companies.

However, the globalization of business has accelerated at a pace that exceeded the ability of companies to meet this need with an adequate number of qualified employees (Stroh \& Caligiuri, 1998; Welch, 1994). The survey states that while companies report an increasing population of professionals on international assignments, 91\% choose their current employees for international assignments rather than new hires. Furthermore, the majority of the companies report that less than $6 \%$ of their assignees were previously assigned internationally. This raises the question of what qualifications companies are looking for in their employees for international assignments.

According to Arthur and Bennett (1995) and Tung (1998), selecting the right person for an international assignment is crucial for its accomplishment. However, making the right selection is not easy (Scullion \&
Collings, 2006). Reviewing the process, Varma, Stroh, and Schmitt (2001) conclude that there are curious anomalies in the selection. The expatriate management literature has identified several criteria based on candidate characteristics. Accordingly, an assignee needs to possess a complex amalgamation of technical, social, organizational, and cultural knowledge and skills (Ghoshal \& Bartlett, 1997). Specifically, these include biological characteristics (Mamman, 1995; Tung, 1981), family situation (Harvey, 1985), job performance (Caligiuri, 1997), technical expertise (Mendenhall, Dunbar, \& Oddou, 1987), completion of previous foreign assignments (Shaffer \& Harrison, 1998), personality traits (Black, 1990; Caligiuri, 2000; Mol, Born, Willemsen, \& Van Der Molen, 2005), and cross-cultural competencies such as cultural adjustment (McEvoy \& Parker, 1995), cultural flexibility (Shaffer, Harrison, Gregersen, Black, \& Ferzandi, 2006), and cultural intelligence (Earley \& Ang, 2003).

The article contributes to the literature by performing an analysis that incorporates the interaction of these factors with features of the assignment such as duration, destination, and task performed, as well as selecting managers' biological background, family situation, and international experiences. It proposes that assignee selection is contingent on the environment, and that the role of candidate characteristics is less significant unless there is a match between these and the assignment features, and a match with manager characteristics based on the homophily paradigm. 
Caligiuri and Tarique (2006) identified three important best practices regarding international assignee selection: realistic previews, self-selection, and candidate assessment in a structured organizational selection program. This article focuses on the latter. Hence, the results would be of interest to selecting managers and human resource professionals who can help develop their employees, as well as individuals who are considering international careers.

\section{2 | QUALIFICATIONS FOR INTERNATIONAL ASSIGNMENTS}

This article first organizes the candidate characteristics that have been extensively studied in the literature, and proposes assignment features and manager characteristics that match with candidate characteristics. A visual of the hypotheses developed can be found in Figure 1.

\section{1 | Candidate characteristics}

Caligiuri, Tarique, and Jacobs (2009) and others in the literature proposed several criteria involving candidate characteristics. This study organizes these under five categories: biological characteristics such as gender, age and ethnicity; family situation, including marital status, and children's schooling; professional qualifications such as experience with company, rank and function, and significant achievements; international experience such as cross cultural training, national background and that of spouse or parents, language skills, and personal or professional international experience; and psychological characteristics.

- Biological background: In 1998, while women represented $47 \%$ of the U.S. workforce (Feltes \& Steinhaus, 1998), they constituted only $13 \%$ of employees on international assignments (Solomon, 1998; Tung, 1998). Linehan and Scullion (2001) conclude that women were still underrepresented. Another potentially salient biological background factor that may create a bias in international assignments is ethnicity. While this factor did not attract as much attention in the literature, Tung (2008) explores if ethnicity matters in international assignments using an Asia-Pacific sample to examine whether candidates with racial backgrounds other than Whites faced a bias.

- Family situation: Spouse and children issues may constitute important challenges for an assignee. This may be a result of economic realities necessitating two-income earners, and that international assignments reduce its likelihood. Shaffer and Harrison (1998) find direct, indirect, and moderating influence of several family-context variables such as family responsibility, spouse adjustment, and satisfaction on decisions of expatriates to quit their assignments. Many other authors also cite the inability of the spouse to adjust as the major cause of expatriate turnover (Adler, 1986; Black \& Stephens, 1989; Harvey, 1985). Furthermore, children of the assignees can have a direct effect on expatriate's satisfaction and adjustment (Shaffer \& Harrison, 1998). Other related literature such as human capital and role theories also predict that employees with children generally tend to experience more work-family conflict (Netemeyer, Boles, \& McMurrian, 1996). This would particularly be the case for children at school age. The women surveyed in Stroh, Varma, and Valy-Durbin (2000) felt strongly that those with children were less likely to accept international assignments.

- Professional qualifications: Several researchers also include technical expertise, previous achievements and experience among relevant factors in international assignee selection (Arthur \& Bennett, 1995; Brewster, 1991; Bjorkmann \& Gersten, 1993; Tung, 1981; University of Manchester Institute of Science and Technology [UMIST], 1995). In fact, the research done about the actual practice shows that technical competence is the most widely used criterion (Bjorkmann \& Gersten, 1993; Brewster, 1991; Gersten, 1990;

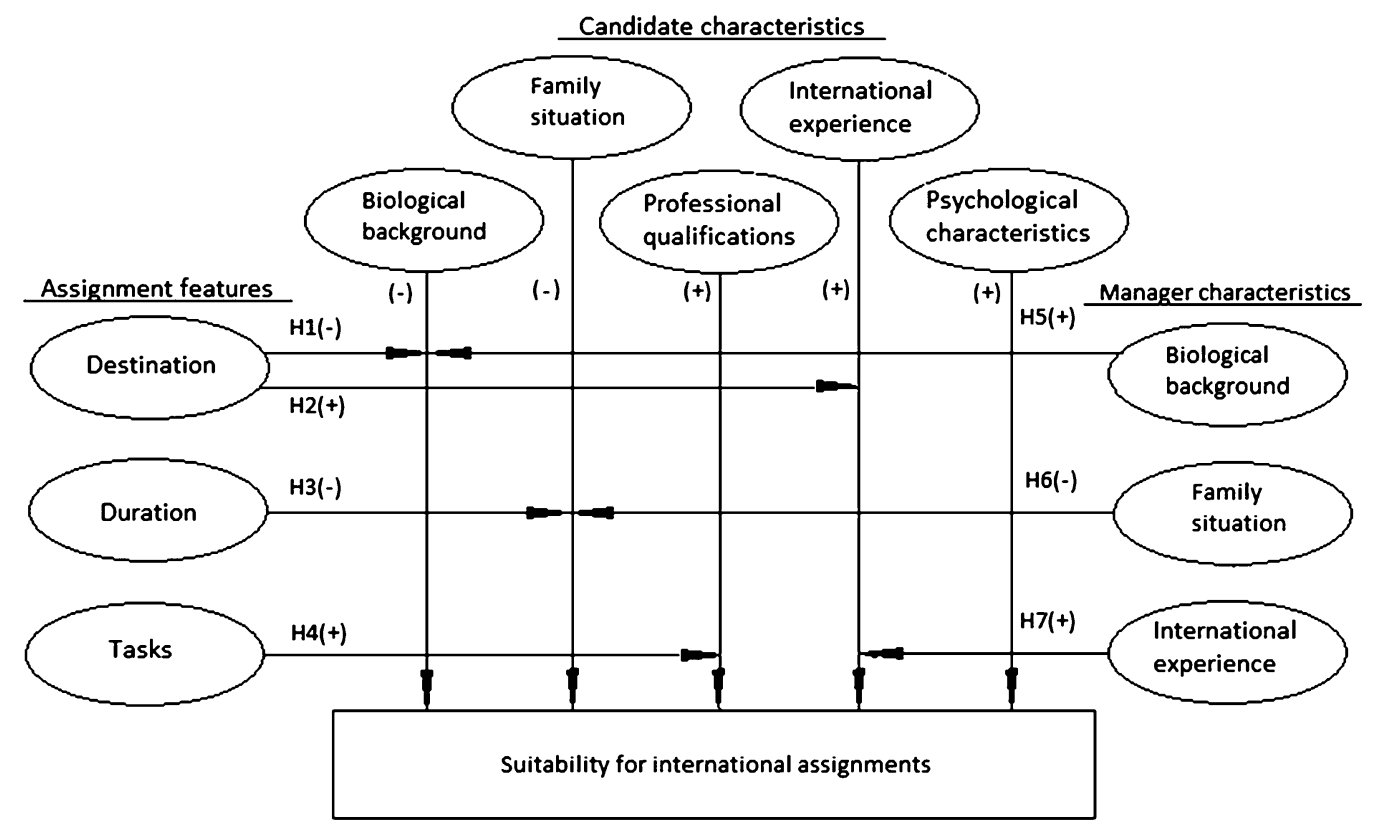

FIGURE 1 The model 
Tung, 1981). There is also some research suggesting that technical competence may be overrated (Kealey, 1990; Tung, 1981).

- International experience: Egan, Bendick, and Miller (2002) find that employers also consider international skills as complements to functional skills rather than substitutes. Research also demonstrates that prior international experience can facilitate an individual's ability to function and work effectively in a host country (Selmer, 2002; Spreitzer, McCall, \& Mahoney, 1997; Takeuchi, Tesluk, Yun, \& Lepak, 2005). Furthermore, international experience can also include having foreign friends or spouses (Searle \& Ward, 1990). The ability to maintain such relationships reflects their cross-cultural skills. This argument can be extended to include individuals' own national background and those of parents.

- Psychological characteristics: Research shows that well-adjusted and high-performing international assignees share certain personality traits (Black, 1990; Caligiuri, 2000; Mol et al., 2005). These personality traits are captured by the five dimensions of human psychology: Assignees are expected to be open and receptive to learning the norms of new cultures, captured by the openness dimension; to initiate contact with host nationals, assessed by their extraversion; to be agreeable and thus demonstrate prosocial behaviors; to gather cultural information by being conscientious; and to handle higher amounts of stress associated with ambiguity of their new environments covered by the neuroticism dimension (Black, 1990).

The criteria considered so far included candidate characteristics that may make them more suitable for international assignments in general. The contingency approach to leadership provides the theoretical support for the role of matching assignment features and manager characteristics with those of the candidates considered for international assignments. Although multiple sets of managerial behaviors were originally identified, two types of behaviors are proven to be especially effective. Initiating structure or task-oriented behaviors provides structure to ensure task completion and goal attainment, such as role assignment (Lawrence \& Lorsch, 1967; Thompson, 1967). This provides support for the importance of matching consistent features of assignments with those of the candidates considered. Additionally, consideration or relation-oriented behaviors include building good rapport and interpersonal relationships and showing support and concern for subordinates (Fiedler, 1964). These type of behaviors justify the role of matching manager and candidate characteristics in international assignee selection. The subsequent research on the topic highlights the importance of various aspects of the environment (Scott, 1981). These contingency factors imply that instead of a one-best-way, effective managers would consider the various aspects. One of the main ideas is that the management must be concerned with achievement alignments and good fits (Morgan, 2007). In the case of international assignee selection, the consistency of candidates with different assignment features and manager characteristics may demonstrate good fit.

\section{2 | Assignment features}

One can argue that significance of candidate characteristics would be contingent on assignment features. There may be some candidate characteristics that make them more attractive because of their consistency with a particular international assignment. For example, a candidate that had international experience may be likely to be selected for an assignment, even if the destination may be different. One can argue that during the prior experience, the candidate acquires cross-cultural adjustment skills that can make him/her also suitable for another location. However, one can also argue that if a candidate had prior international experience in the same destination, he/she may be considered more favorable due to this destination-specific experience. The literature identified three assignment features with which candidate characteristics can be consistent. These are destination, duration, and task performed. Out of 15 possible such interactions of five candidate characteristics with these three assignment features, there are four suggested, as follows:

\subsection{1 | Destination}

Several studies examined why a disproportionately small percentage of women were selected (Adler, 1984a, 1984b; loannou, 1994). In particular, Adler (1984a, 1984b, 1986) explores various "myths" about women in international business. These include that companies refuse to send women overseas due to various reasons, and that foreigners' prejudice against women render them ineffective. Adler (1984a) notes that management in more than half of the companies hesitated to send women abroad. One explanation Adler (1984b) offers is that women encountered more prejudice on international assignments (Caligiuri \& Cascio, 1998; Tung, 1998). Thal and Cateora (1979) also state that women find their career paths blocked by the cultural biases of foreign businesses. Frontczak and Cateora (1988) indicate that this prejudice is of varying degrees from one country to another. Izraeli, Banai, and Zeira (1980) add that human resource professionals were concerned that women would feel lonely, isolated, and sexually harassed. Research on effectiveness of working in culturally tough countries shows conflicting results about women expatriates. According to Tung (1998), and Stroh et al. (2000), women assigned to culturally challenging countries are quite effective, even though they may initially experience prejudice. Westwood and Leung (1994) and Adler (1987) suggest that for female expatriates working in Asian countries, their gender did not stand in the way of their performing their jobs. In fact, Taylor and Napier (1996) and Adler (1987) suggest that being a female is an advantage because it gives women more visibility and enables them to have stronger interpersonal relationships, and since they are used to trying harder (Yochanan \& Shortland, 2001). Some destinations may also present challenges for assignees with non-White ethnicities. Societies at some locations may have not evolved into pluralism, where distinct ethnic groups are accepted. Pluralism offers the benefit of fostering an environment of mutual respect (Tung, 1993), leading to a mind-set conducive to developing solutions (Harvey, Novicevic, Buckley, \& Fung, 2005). In contrast, a bias can negatively impact the contribution of the assignees (Harvey et al., 2005). Recognizing that this negatively affects a company's competitive posture (Feely \& Harzing, 2003; Kefales, 1998; Paul, 2000), such ethnic minorities may be overlooked for certain destinations. 
Hypothesis 1: Female or non-White candidates are less likely to be selected for international assignments at challenging destinations because of their gender and ethnicity.

Several studies have shown that an assignee selection was largely influenced by cross-cultural adjustment to the new culture (Mendenhall, Kuhlmann, Stahl, \& Osland, 2002). Mol et al. (2005) find that local language ability is a positive factor in assignee selection. Many researchers also noted a positive relationship between language skills and assignment destination (Bhaskar-Shrinivas, Harrison, Shaffer, \& Luk, 2005; Mol et al., 2005; Shaffer et al., 1999). Clearly, language skills are destination specific. Ability to speak the language of the destination improves the communication, but these skills are also crucial for cross-cultural adjustment (Cui \& Van Den Berg, 1991). When one is studying a foreign language, he/she also acquires the correct behaviors to display during communication, further increasing the likelihood of selection (Cui \& Van Den Berg, 1991).

The social learning literature suggests that the more contact assignees have with nationals of a destination and their culture, the greater their cross-cultural adjustment at that destination is (Bochner, Hutnik, \& Furnham, 1986; Brislin, 1981). These contacts could be a result of a spouse and parents from the destination country, even candidates themselves, or prior personal or professional visits to that destination. There are many ways assignees can improve their likelihood of adjustment. One additional option is destination-specific cross-cultural training before departure (Black \& Mendenhall, 1990). Overall, these suggest that candidates with past international experiences might render them more favorable in the selection process for assignments at consistent destinations.

Hypothesis 2: Candidates with destination-consistent international experiences are more likely to be selected for corresponding international assignments.

\subsection{2 | Duration}

Reiche and Harzing (2009) identify several forms of international assignments varying in duration. Among these are short-term, longterm, and virtual assignments. Short-term assignments range between 1 and 12 months (Collings et al., 2007). They are typically unaccompanied by family, and are particularly useful when specific skills need to be transferred. These short-term assignments are also referred to as international business travel or frequent flyer assignments (Welchfg, 2007). Long-term assignments last longer than a year and are more complex, not only due to regulations that need to be met in the destination country but also in terms of implications on the family of the assignee. Unlike these, virtual assignments do not require the individual to physically relocate. Such assignments distribute international responsibilities as managed from an individual's home base (Welch, Worm, \& Fenwick, 2003).

It is easily conceivable that managers look for different characteristics in assignees depending on the duration of the assignment. Their ability to complete the assignment may vary for different duration, and candidates' specific characteristics may differently affect their likelihood of selection. For example, while the family situation might not be relevant for virtual assignments, it may be important for longterm assignments. The family may need to move to the destination of the assignment, which can create hardship for the spouse, who may have to quit his/her job and may have difficulty finding one in the destination (Adler, 1986; Black \& Stephens, 1989). Similarly, there may be further issues when the assignee has children (Shaffer \& Harrison, 1998; Netemeyer et al., 1996). Their adjustment might not be easy, and the move may negatively affect their education, if they are at school age. For the company itself, too, relocating such a candidate would impose additional costs since most likely they would have to develop programs to assist their employees with moving the whole family as well as finding employment for the spouse and good quality schools for their children.

Hypothesis 3: Candidates are considered less likely to be selected for international assignments with duration that are inconsistent with their family situation.

\section{3 | Tasks to be performed}

Tung (1981) identifies technical competence among the group of variables considered in assignee selection. While more recent studies have empirically confirmed that expatriate selection was a multifaceted subject and that personality characteristics as well as interpersonal skills were very important (Caligiuri, 2000; Spreitzer et al., 1997), in practice most companies still use technical competence and knowledge of company systems as the primary selection criterion (Harris \& Brewster, 1999; Sparrow, Brewster, \& Harris, 2004). The assignees need to be equipped with necessary knowledge, technical skills, and professional experience that enable them to perform the job that needs to be completed. Hence, it makes sense to select a candidate with technical expertise, as demonstrated by years of experience, or those with significant past achievements. One can also argue that the candidate's level within the organization, such as executive, director, and so on, may indicate higher potential for selection. Bonache, Brewster, and Suutari (2001) identify additional reasons for consistency of professional experience with tasks to be performed during an international assignment: the difficulty to identify and measure relevant interpersonal and cross-cultural competencies, managers who circumvent selection process of human resources, and self-interest of the selectors. Hence, managers might be drawn to candidates with technical skills that match the job to be performed due to its ease.

Hypothesis 4: Candidates with consistent professional qualifications to the tasks involved are more likely to be selected for corresponding international assignments.

\section{4 | Manager characteristics}

\subsection{1 | Biological background}

Stroh et al. (2000) argue that another important overlooked factor is the supervisor. Several studies suggested that the supervisor-subordinate 
relationship might be a critical determinant in selection. Varma et al. (2001) explore this using the leader-member exchange model. The theory proposes that supervisors classify their subordinates into two groups-in-group and out-group-on the basis of their negotiated roles. In-group means that the supervisor believes the subordinate is motivated to assume greater responsibility in the organization (Liden \& Graen, 1980). This responsibility can take the form of an international assignment. Often, employees who serve the company under hardship of international assignment are considered for promotion and other opportunities that advance their careers (Thal \& Cateora, 1979). Dienesch and Liden (1986) suggest that the key to determine the quality of the leader-member or supervisor-subordinate relationship is nonperformance individual characteristics such as ethnicity and gender. Within this context, the homophily paradigm also proposes that individuals who share certain characteristics in common elicit positive responses in one another, and hence form positive relationships (Byrne, 1971). The literature on in-group favoritism, too, suggests that gender and racial similarity are relational characteristics that enhance supervisor-subordinate relationships (Chattopadhyay, Tluchowska, \& George, 2004; Vecchio \& Bullis, 2001).

While searching for evidence, Ibarra (1992) finds that men tend to show a much higher degree of homophily than women. In contrast, women who need foreign assignments to advance may find their career paths blocked by the cultural biases of their own corporations (Thal \& Cateora, 1979), as international experience is often considered an important requisite for top management positions, especially in multinational companies. One reason provided for fewer women on international assignments was that they did not have sponsors (Linehan \& Scullion, 2001). In fact, Chusmir and Frontczak (1990) argue that qualified women are overlooked because men make these decisions. Similar arguments can also be made with regard to the ethnicity of the candidates and their supervisors. Elsass and Graves (1997) argue that social identity and categorization processes are likely to evoke a racial among other similarity bias that members will identify with other members who share their category memberships. A potential outcome of this similarity bias is favoritism toward racially similar individuals (Ashforth \& Mael, 1989; Tsui \& Gutek, 1999).

Hypothesis 5: Managers are more likely to select candidates with the same gender and ethnicity for an international assignment.

\subsection{2 | Family situation}

The above argument can be extended to include the marital and children situation but with the opposite implication. Married or separated managers with children are certainly aware of difficulties international assignments present for the personal lives of assignees, their spouse, and school-age children. It can be argued that reflecting on their own past experiences, they may not select married candidates with school-age children. There is support for this argument from the literature on burnout. Theoretical models of burnout such as Numerof (1983) and Perlman and Hartman (1982) cite the importance of supervisory behavior. Golembiewski, Munzenrider, and Stevenson
(1986) suggest that personal characteristics lead to burnout and consequently poor performance. Leadership skills of supervisors are found to be related to subordinate burnout in Seltzer and Numerof (1988), where leadership explained a significant portion of the variation in burnout on top of traditional factors such as marital status. Hence, one can conclude that managers with leadership skills can draw from their own personal characteristics, past or current, and act to reduce burnout in their subordinates.

Hypothesis 6: Managers are less likely to select candidates with similar past or current family situation for an international assignment.

\subsection{3 | International experience}

A further extension of the above arguments on the implications of managers' self-reflection in making a selection includes their own international experiences. In the international assignments the managers themselves completed during their careers, they might have observed the benefits of having prior international experiences, and therefore this may provide additional reasons for their more favorable view of candidates with such experiences. Of course, this could also work in the opposite direction. That is, managers may think that their prior international experience has not helped them in a significant way or may have negatively affected in terms of reinforcing previously held stereotypical beliefs about other countries or foster negative, unrealistic expectations for the foreign culture (Bandura \& Locke, 2003).

Hypothesis 7: Managers with international experience are more likely to select candidates with international experience for an international assignment.

\section{I DATA AND METHODOLOGY}

A survey among graduate business students in an MBA program at a midwestern university was carried out to obtain the data analyzed. The students were asked to take the role of managers making determinations on the suitability of each candidate for the international assignments described in the survey. The assignments considered were hypothetical. Use of MBA students as proxy for decisionmaking managers was done in several other contexts (Apesteguia, Azmat, \& Iriberri, 2012; Arce \& Li, 2011; Friedman, Chi, \& Liu, 2006; Hui, Au, \& Fock, 2004). In particular, this article's use of MBAs is fairly similar to that in Tung (2008), where MBA students were given descriptions of potential candidates for international assignments and were asked to rank-order them. The students in this study had significant managerial experiences involved in real-life decision-making processes. To further establish the validity of the results, the analysis was repeated utilizing a restricted sample that contained graduate students with at least 10 years of professional experience. Their responses are used to assess how experienced managers' priorities would be different in the selection criteria. Overall, 135 MBA students were surveyed over 2012-2014, of which 47 are experienced 
managers. The MBA students were presented with the descriptions of five international assignments and seven candidates. Hence, each student evaluated 35 different possible pairings of candidates and assignments, leading to 1,645 ratings by experienced managers, and 4,725 ratings overall. Separate regression analyses were carried out for each sample.

The candidates varied in sociobiological background, professional qualifications, international experience, and psychological characteristics. Candidates varied in biological characteristics such as age, gender, and ethnicity. There was also variation among candidates' family situations. Among the candidates, there were also differences in terms of professional experience. These include significant to shortterm experiences at the company and overall; different levels of responsibilities at the company; some with significant achievements that may or may not match their years of experience; and various functional backgrounds related or not related to tasks to be performed. The candidates under consideration further varied in terms of their international experience. Some candidates had extensive experiences at same destinations and some have only a few in various countries. Finally, the candidates' psychological characteristics were differentiated.

The assignments varied in duration, destination, and function and tasks performed. Challenging destinations such as China, Brazil, and India were chosen to be the destinations in some assignments. Another destination was the United Kingdom, presumably a country that would be one of the easiest for U.S. nationals, given the language and cultural similarities. This assignment feature was included in the survey to assess Hypotheses 1 and 2. The assignments included had variety in their duration, including short, long, and virtual assignments, to see their implication on the candidates' ratings as in Hypothesis 3. Finally, there were different tasks involved in assignments for testing of Hypothesis 4.

The average age of MBA students acting as managers was 31; $68 \%$ were White, and $67 \%$ were males. Nearly half of them were married, but $58 \%$ did not have children. One-third of those surveyed have school-age children, and $69 \%$ were children of U.S. citizens. Of these, the overwhelming majority had U.S.-citizen spouses. Sixty-nine percent of those with foreign parents were also born outside the United States. Nearly half of these had also foreign-born spouses. Overall, there was sufficient variation in managers' biological background, family situation, and international experience to produce statistically meaningful results to test the hypotheses, and this information was used to test Hypotheses 5, 6, and 7, respectively.

Prior to regression analysis, several adjustments were made to the original data, particularly for the candidate characteristics, given the degrees of freedom issues that arise in analyzing the ratings of seven different candidates for five assignments. These are explained in the following section. The summary description of the resulting variables can be found in Table 1.

\section{1 | Dependent variable}

\subsection{1 | Ratings}

Seven candidates were rated on a scale of 0 to 100 to assess their suitability for each of five international assignments. Naturally, there is variation in ratings across managers, leading to different averages and standard deviations. To address this, their z-scores were analyzed, where for each manager their mean was subtracted from each raw rating divided by the standard deviation. This method rescaled the average score for each manager to zero. This allowed an analysis of the implications of, at most, seven candidate characteristics and five assignment features on comparable rating distributions across managers.

\subsection{Independent variables}

\subsection{1 | Candidate characteristics Biological background}

There were three variables considered under this category: age, gender, and ethnicity of the candidates. Indicator variables were introduced to the regression model for the latter two, set to 1 when the candidate was female or non-White. A principal component analysis (PCA) reveals that two out of three dimensions of biological background, that is, age and gender, are well represented in the resulting variable, whereas ethnicity is not well captured. Hence, ethnicity is included in the analysis as a separate variable.

\section{Family situation}

The impact of the candidates' marital status and children was assessed under this category. Three indicator variables were used. The marital status indicator was set to 1 if they were married. A similar approach was taken for the children and school-age children indicators. PCA analysis showed low commonality for marital status. Hence, this variable was included in in the regression analysis separately.

\section{Professional qualifications}

There were four variables corresponding to the professional qualifications of the candidates: years of experience at the company and overall, level at the company, and whether they had any significant achievements. An indicator variable was used in the model for the level, set to 1 if the candidate was a director or an executive. The correlation coefficient of this variable with the indicator variable of significant achievements was 1 . Hence, the latter was excluded. PCA showed that all remaining variables were well represented in the resulting variable.

\section{International experience}

Various aspects that related to their international experience were used to assess the importance of this candidate characteristic for any international assignment. However, considering the degrees of freedom with respect to candidate characteristics, there was room for only one variable for their international experience, and another for their psychological characteristics. Therefore, an index was developed that summed the components of four primary dimensions of international experience: personal/professional experience of candidates in other countries; cross-cultural training; foreign language skills; and own, spousal, and parental national background. Each of these dimensions were assumed to have equal importance, contributing, at most, 
TABLE 1 Hypotheses variables in the model and their description

\begin{tabular}{|c|c|}
\hline \multicolumn{2}{|l|}{ Assignment features: } \\
\hline \multicolumn{2}{|l|}{ H1: Destination $\times$ biological background $(-)$ : } \\
\hline Challenging destination & Challenging destination (1 if Brazil, India, or China) \\
\hline Challenging destination $\times$ ethnicity & Interaction of challenging destination and ethnicity ( 1 if non-White) \\
\hline \multicolumn{2}{|l|}{ H2: Destination $\times$ international exp. $(+)$ : } \\
\hline P.C. (Destination $\times$ int'l. exp. 1) & Principal component of following matching int'l. experiences: \\
\hline \multirow[t]{2}{*}{ P.C. (Destination $\times$ int'l. exp. 2) } & Principal component of following matching int'l. experiences: \\
\hline & Foreign language, national background (self, parent) \\
\hline \multicolumn{2}{|l|}{ H3: Duration $\times$ family situation (-): } \\
\hline Duration & Duration (1 if 2 years) \\
\hline P.C. (Duration $\times$ family sit. 1 ) & Principal component of following matching family situations: \\
\hline \multicolumn{2}{|l|}{ H4: Task $\times$ professional qualifications (+): } \\
\hline Task & Strategic ( 1 if task is strategic) \\
\hline \multirow[t]{2}{*}{ Task $\times$ function } & Interaction of task and function \\
\hline & ( 1 if task of assignment matches function of candidate) \\
\hline \multicolumn{2}{|l|}{ Manager characteristics: } \\
\hline \multicolumn{2}{|c|}{ H5: Biological back. (man.) × biological back. (can.) (+): } \\
\hline Gender (man.) & Gender ( 1 if female) \\
\hline Gender (man.) × Gender (can.) & Interaction of gender for manager and candidate ( 1 if same) \\
\hline Ethnicity (man.) & Ethnicity ( 1 if non-White) \\
\hline \multicolumn{2}{|c|}{ H7: International exp. (man.) $\times$ international exp. (can.) (+): } \\
\hline \multirow[t]{2}{*}{ P.C. [Int'I. exp. (man.)] } & Principal component of following international exp. for manager: \\
\hline & National background (self, spouse, parent) \\
\hline \multirow[t]{4}{*}{ P.C. [Int'l. exp. $(\operatorname{man}) \times$ int'l exp. (can.)] } & Principal component of following matching International exp. \\
\hline & for manager and candidate: \\
\hline & National background (self, spouse, parent) ( 1 if manager and \\
\hline & candidate are 1 for each separately) \\
\hline
\end{tabular}

1 toward the resulting index: 0.5 was added to the sum each time a candidate had personal or professional experience in a foreign country; 1 for cross-cultural training; 0.5 or 1 if the candidate spoke some or was fluent in another language, respectively; and $1 / 3$ for each non-U.S. national background of the candidate, spouse, and parents.

\section{Psychological characteristics}

The candidates are more likely to be selected for any international assignment if they are extravert, agreeable, conscientious, emotionally stable, and open. It is unfortunately not possible to distinguish the relative importance of each of these psychological dimensions separately due to low degrees of freedom. Hence, as in the case of international experience, an index is built that sums each of these dimensions, adding 2 if the candidate holds each of the above mentioned characteristics, 1 if they had some, and -1 or -2 if they have some or fully opposing characteristics. This results in an index that can vary between 10 and -10 .

\subsection{2 | Assignment features}

\section{Destination}

As formulated in Hypotheses 1 and 2, the destination of an international assignment can be inconsistent with the gender and ethnicity of the candidate, or consistent with their international experience, making them less or more likely to be selected, respectively. Challenging destinations present difficulties for minorities such as female and/or non-White assignees. Conversely, a candidate can have 
specific international experience that prepared him/her better for assignments in these destinations. To capture these, an indicator variable for the destination as well as its interaction with candidates' biological background and international experience are added to the model. The indicator variable assumes the value of 1 if the destination is challenging, which is the case in Brazil, India, and China. Two separate interactions are considered with gender and ethnicity: If the candidate is female or non-White, respectively, for a challenging destination. Similarly, PCA results in two interaction variables that captures the consistency of international experience with the destination. PCA shows high measures in the pattern matrix for one of the components for a consistent spousal national background and personal or professional experience, and low measures for a consistent self or parental national background or consistent language skill for the same component. The measures in the pattern matrix are high for the latter group for the other component and low for the first group. Therefore, two separate interaction of destination with various dimensions of international experience are considered in the analysis. One interaction is if the candidate had a prior personal or professional experience in this particular destination or spouse has national background there. The other interaction is when the candidate has skills in the foreign language of the destination or candidate or parents have national background there. Note that this type of grouping of consistent international experience make sense as one can categorize the latter experiences more direct, and the former experiences as of lesser significance.

\section{Duration}

Hypothesis 3 suggests that family situation of a candidate can be inconsistent with assignment duration. In particular, a candidate can potentially be seen less favorable for a long international assignment if married or has children, particularly of school age. To analyze this, an indicator variable for duration is added, which is set equal to 1 if the duration is for 2 years as well as its interactions. This represents long assignments consistent with definitions in the literature (Welch et al., 2003). All three interactions are well represented in the variable resulting from PCA.

\section{Task to be performed}

One last dimension of an international assignment that can interact with candidate characteristics is task performed at the destination. The candidate can have a consistent functional professional qualification rendering him/her more likely to be selected for the assignment, as stated in Hypothesis 4. To assess this, an indicator variable for the task and an interaction variable for task-consistent function of the candidate are considered. Note that, unfortunately, it is not possible in this study to consider the impact of each different task in the ratings due to degrees of freedom associated with five assignments considered. Instead, the indicator variable for task is set equal to 1 if the task is strategic.

\subsection{3 | Manager characteristics}

\section{Biological background}

Hypothesis 5 states that similarity in gender and ethnicity of managers and candidates results in more favorable rating for a candidate. In other words, say female managers favor female candidates or White managers favor White candidates. To capture these, two indicator variables on the gender and ethnicity of the managers are considered. These are defined in the same way as those for candidates, and assume value of 1 if they are female, and 1 if they are non-White. Additionally, interactions between gender and ethnicity of the manager and candidates are analyzed, set to 1 if the genders/ ethnicities match.

\section{Family situation}

The survey also asks information on the marital status and children of the managers. Hypothesis 6 states that managers can draw from their own past experiences and this may result in less favorable ratings for candidates that are married and have school-age children. Hence, two indicator variables about managers' family situation are added as well as their interaction with the marital status indicator and the school-age children indicator of the candidate. Note that to draw from one's own experiences about the implications of marital status and children, a manager does not need to be currently married or have school-age children, respectively. He/she can also be divorced or just have (non-school-age) children. Hence, these indicator variables are constructed to be equal to 1 for married or divorced, and 1 for school-age or otherwise children of managers, respectively.

\section{International experience}

The information on the survey about the international experience of managers is limited to their own, spousal, and parental national background. Hence, to test Hypothesis 7 on whether having such non-U.S. national background would be seen as more favorable by a manager who draws from his/her own experiences with such background, a variable on manager's international experience and its interaction with that of candidate are considered. PCA results in one variable that captures all three aspects of national background of the manager. Similarly, based on results of PCA, only one variable is needed to capture the interactions of matching non-U.S. national background of manager and candidate. Note that, here, by matching, only having a non-U.S. national background is needed for manager and candidate, and same nationality is not sought.

Table 2 provides the correlation matrix for the variables representing candidate characteristics, assignment features and manager characteristics included in the analysis. It is interesting that the correlation coefficients among variables within these three broad groups is nearly zero, and higher for variables within the same group. In particular, the correlation of the PCA variable for professional qualifications is high with the one for age and gender, and with the psychological characteristics, which are both realistic. With age, professional qualifications increase; and the same psychological characteristics that make a person more qualified in international assignments are likely to positively impact their overall professional careers.

\section{4 | RESULTS}

Regression results are presented in Table 3. The analysis is done separately for all managers and also for managers aged 32 or higher, to observe if and how the importance of factors considered in the assignee selection change with more experienced managers. In both analyses, 
TABLE 2 Correlation matrix

\begin{tabular}{|c|c|c|c|c|c|c|c|c|c|c|c|c|c|c|c|}
\hline Variable & 0 & 1 & 2 & 3 & 4 & 5 & 6 & 7 & 8 & 9 & 10 & 11 & 12 & 13 & 14 \\
\hline \multicolumn{16}{|l|}{ Rating } \\
\hline 1. P.C. (age, gender) & 0.12 & & & & & & & & & & & & & & \\
\hline 3. P.C. (children, school age) & 0.27 & 0.41 & 0.15 & & & & & & & & & & & & \\
\hline 4. Marital st. & -0.23 & 0.32 & 0.17 & -0.15 & & & & & & & & & & & \\
\hline 5. P.C. (all prof. qual.) & 0.28 & 0.74 & 0.28 & 0.70 & 0.05 & & & & & & & & & & \\
\hline 7. Psychological char. & 0.22 & 0.31 & 0.29 & 0.17 & -0.29 & 0.63 & 0.32 & & & & & & & & \\
\hline 8. Challenging destination & 0.02 & 0.00 & 0.00 & 0.00 & 0.00 & 0.00 & 0.00 & 0.00 & & & & & & & \\
\hline 9. Duration & 0.03 & 0.00 & 0.00 & 0.00 & 0.00 & 0.00 & 0.00 & 0.00 & -0.61 & & & & & & \\
\hline 10. Task & -0.04 & 0.00 & 0.00 & 0.00 & 0.00 & 0.00 & 0.00 & 0.00 & 0.41 & 0.17 & & & & & \\
\hline 11. Gender (man.) & 0.00 & 0.00 & 0.00 & 0.00 & 0.00 & 0.00 & 0.00 & 0.00 & 0.00 & 0.00 & 0.00 & & & & \\
\hline 15. P.C. [Int'I. exp. (man.)] & 0.00 & 0.00 & 0.00 & 0.00 & 0.00 & 0.00 & 0.00 & 0.00 & 0.00 & 0.00 & 0.00 & -0.02 & -0.66 & -0.16 & -0.19 \\
\hline
\end{tabular}

F-statistics are significant at $99.9 \%$, and the adjusted $R^{2}$ is about .40 . Along with the coefficients for various factors and their significance, the table provides the percentage of the variation explained by each to indicate their relative importance in assignee selection.

The results point to the importance of considering the consistency of assignment features with candidate characteristics in the selection. The consideration for matching factors renders several of candidate characteristics on suitability for any assignment of little importance. On candidate characteristics alone, the results do, however, show support for positive impact professional qualifications and appropriate psychological characteristics on the suitability of a candidate for an international assignment. However, their combined effect only explains less than $3 \%$ of the variation in the ratings. Note that the positive effect of appropriate psychological characteristics become insignificant for experienced managers. There is some support biological background of candidates negatively impacting their selection, when age and gender is considered, but not ethnicity. Contrary to expectations, family situation, particularly having children positively and international experience negatively explains suitability for an assignment. This implies, for example, that ability to speak French, does hurt selection of a candidate to an assignment in India. This may be explained in nongeneralizability of a country-specific experience in other destinations. Overall, candidate characteristics explain less than $9 \%$ of the variation in ratings for any assignment for all managers, and they become less important in the selection for experienced managers.

While candidate characteristics alone do not seem to be critical in the selection for any assignment, their consistency with assignment features explains about $90 \%$ of the variation in the ratings for both all and experienced managers. Accordingly, candidates' characteristics need to be consistent with destination, duration, and task performed in an assignment for selection. The results show support for all hypotheses that relate to assignment features (i.e., Hypotheses 1-4). Inconsistent biological background makes candidates less likely to be selected, such as female and non-White candidates in challenging destinations. Furthermore, destination-consistent international experiences improve the likelihood of a candidate's selection for that assignment as reflected in the positive coefficients of both interaction variables. In contrast, supporting Hypothesis 3, family situation hurts their chances of selection for long assignments that may require relocation. Marital status seems to lose its significance for experienced managers, though. Most importantly, it seems managers are looking for consistency of task performed in an assignment and professional qualifications of a candidate. This explains nearly $40 \%$ of the variation in ratings, and becomes an even more important factor for experienced managers, while consistent international experience and family situation lose importance for experienced managers. The second most important criteria for both all and experienced managers is the consistency of the destination with past international experiences of the candidates, explaining slightly above $30 \%$ of the variation in the ratings.

The results do not provide much support for hypotheses on consistent manager and candidate characteristics. There is no statistically significant support for Hypothesis 5. Particularly experienced managers do not favor candidates of the same sex or ethnicity as them. Managers with international experience in terms of national background do not necessarily select those candidates with similar experiences for an assignment. There is some support for Hypothesis 6. Managers draw from their own experiences as being married and having school-age children, and consider candidates with such family situation less likely to be selected for any assignment. These explain most of the matching manager-candidate characteristics at about $2 \%$ to $4 \%$, for all and experienced managers, respectively. While the negative impact of shared marital status seems to lose its significance for experienced managers, experienced managers with children, seem to pay more attention to the candidates with children and favor them less.

\section{5 | THEORETICAL AND PRACTICAL IMPLICATIONS}

This study examined the relative significance of factors considered in the selection of a candidate for international assignments. The 
TABLE 3 Regression results

\begin{tabular}{|c|c|c|}
\hline Variable & $\begin{array}{l}\text { All } \\
\text { managers }\end{array}$ & $\begin{array}{l}\text { Experienced } \\
\text { managers }\end{array}$ \\
\hline Candidate characteristics: & $8.7 \%$ & $6.3 \%$ \\
\hline Biological background (-): & $0.8 \%$ & $0.3 \%$ \\
\hline P.C. (age, gender) & $-0.212^{* * * *}$ & -0.171 \\
\hline Ethnicity & 0.074 & 0.005 \\
\hline Family situation (-): & $4 \%$ & $3.9 \%$ \\
\hline P.C. (children, school age) & $0.218^{* * * *}$ & $0.287^{* * *}$ \\
\hline Marital st. & $0.170^{*}$ & 0.115 \\
\hline Professional qualifications (+): & $2.0 \%$ & $1.0 \%$ \\
\hline P.C. (all prof. qual.) & $0.398^{* * * *}$ & $0.342^{* *}$ \\
\hline International experience (+): & $1.3 \%$ & $0.7 \%$ \\
\hline International exp. & $-0.146^{* * *}$ & $-0.121^{*}$ \\
\hline Psychological characteristics (+): & $0.7 \%$ & $0.4 \%$ \\
\hline Psychological char. & $0.031^{* * *}$ & 0.025 \\
\hline Assignment features: & $89.0 \%$ & $89.2 \%$ \\
\hline $\begin{array}{l}\text { H1: Destination } \times \text { biological } \\
\text { background }(-) \text { : }\end{array}$ & $2.9 \%$ & $4.2 \%$ \\
\hline Challenging destination & $0.249^{* * * *}$ & $0.370^{* * *}$ \\
\hline Challenging destination $\times$ gender & $-0.249^{* * * *}$ & $-0.301^{* * * *}$ \\
\hline Challenging destination $\times$ ethnicity & $-0.329^{* * * *}$ & $-0.354^{* * *}$ \\
\hline $\begin{array}{l}\text { H2: Destination } \times \text { international } \\
\quad \text { exp. }(+) \text { : }\end{array}$ & $34.5 \%$ & $32.7 \%$ \\
\hline P.C. (Destination $\times$ int'l. exp. 1) & $0.215^{* * *}$ & $0.202^{* * *}$ \\
\hline P.C. (Destination $\times$ int'l. exp. 2) & $0.259^{* * * *}$ & $0.251^{* * * *}$ \\
\hline H3: Duration $\times$ family situation (-): & $11.8 \%$ & $8.3 \%$ \\
\hline Duration & $0.227^{* * * *}$ & 0.135 \\
\hline P.C. (duration $\times$ family sit. 1 ) & $-0.255^{* * *}$ & $-0.227^{* * *}$ \\
\hline Duration $\times$ marital st. & $-0.202^{* * * *}$ & -0.075 \\
\hline $\begin{array}{l}\text { H4: Task } \times \text { professional } \\
\text { qualifications }(+):\end{array}$ & $39.7 \%$ & $44.0 \%$ \\
\hline Task & $-0.098^{* * * *}$ & -0.084 \\
\hline Task $\times$ function & $0.714^{* * *}$ & $0.747^{* * *}$ \\
\hline Manager characteristics: & $2.3 \%$ & $4.5 \%$ \\
\hline $\begin{array}{l}\text { H5: } \text { Biological back. (man.) } \times \text { biological } \\
\text { back. (can.) (+): }\end{array}$ & $0.1 \%$ & $0.7 \%$ \\
\hline Gender (man.) & 0.002 & -0.012 \\
\hline Gender (man.) × gender (can.) & 0.004 & -0.065 \\
\hline Ethnicity (man.) & -0.007 & 0.018 \\
\hline Ethnicity (man.) $\times$ ethnicity (can.) & 0.035 & -0.063 \\
\hline $\begin{array}{l}\text { H6: Family situation (man.) } \times \text { family } \\
\text { situation (can.) }(-) \text { : }\end{array}$ & $2.2 \%$ & $3.8 \%$ \\
\hline Children (man.) & $0.076^{* *}$ & $0.163^{*}$ \\
\hline Children (man.) $\times$ school age (can.) & $-0.187^{* * *}$ & $-0.396^{* * *}$ \\
\hline Marital st. (man.) & 0.058 & 0.085 \\
\hline Marital st. (man.) × marital st. (can.) & $-0.123^{* * * *}$ & -0.175 \\
\hline $\begin{array}{l}\text { H7: International exp. } \\
\quad(\text { man.) } \times \text { international exp. (can.) (+): }\end{array}$ & $0.0 \%$ & $0.0 \%$ \\
\hline P.C. [Int'l. exp. (man.)] & 0.000 & -0.010 \\
\hline $\begin{array}{l}\text { P.C. [Int'l. exp. (man.) × int'l. exp. } \\
\text { (can.)] }\end{array}$ & 0.000 & 0.009 \\
\hline N & 4725 & 1645 \\
\hline Adjusted $R^{2}$ & 0.399 & 0.400 \\
\hline F statistic & 756 & 247 \\
\hline
\end{tabular}

Note: Coefficients marked with ${ }^{*}, * *, * * *$ are significant at $90 \%, 95 \%, 99 \%$, respectively. expatriate management literature on the topic primarily focused on criteria based on a complex combination of candidate characteristics including biological characteristics, family situation, job performance, technical expertise, completion of previous foreign assignments, personality traits, and cross-cultural competencies such as cultural adjustment, cultural flexibility and cultural intelligence. Varma et al. (2001) conclude that the resulting criteria sometimes yield inconsistencies. Focusing on organizational selection process, this study incorporated the roles that various aspects of the environment play, as suggested for effective management by contingency theories (Scott, 1981), according to which the best choice may be dependent on the fit with the task and relationships (Morgan, 2007). Implication of this resulted in accounting for the role of matching assignment features and manager characteristics with those of the candidates considered in international assignee selection.

The analysis results are particularly helpful for human resources professionals in organizations involved in structured organization selection program for international assignments looking for the primary selection criteria. Is it the technical competence of the candidate? Or his/her personality characteristics? Or knowledge of company systems? According to the analysis results, considering only the suitability of candidate characteristics for an international assignment, family situation, primarily with respect to children, professional qualifications and psychological characteristics seem important in that order. Family situation loses its significance particularly in the eyes of more experienced managers. However, the contingency of the assignments with different features renders the role of candidate characteristics as the only selection criteria less important, and consistency of candidate characteristics with features of the assignment becomes more critical. In particular, it seems professional qualifications that are consistent with the task, and international experience that are consistent with the destination of the assignment become the most important two selection criteria. When managers' characteristics are also taken into account, family situation slightly gains some importance, especially by managers who reflect on their past experiences with their own families. While these guide the decision-making managers or human resource specialists with the selection, there is also one more consideration for multinational companies. As companies are looking into new markets, hiring immigrants with functional background in their line of business might be a good investment. These employees with their familiarity in cultures and practices in both home country and these international markets can play a bridge role, reduce liability of foreignness and help avoid potential negative implications resulting from unfamiliarity.

The results are also useful for employees that are interested in advancing their careers within the company by taking on international assignments. It seems it is more likely for them to be selected for assignments within their own functional area, and for that it is important to gain international experience specific to that destination. It is advisable to learn the language of the main markets of their companies or those of markets they intend to expand their business, have some personal experience there in terms of visits, and demonstrate successful relationships such as friendships or marriage, or countryspecific cultural training. Results also show that it is advisable to express interest in international assignments early in one's career 
when someone is single with no children, as a later start may prove to be more difficult.

The analysis has several limitations. This includes the use of MBA students as managers to assess suitability of candidates to various international assignments. However, the fact that a reduced sample of respondents with an expected 10 years of experience produces very similar results is encouraging. Also, the study was designed to create a very realistic situation that decision-making managers face, where there are candidates with many different characteristics to consider. This, of course, resulted in a degrees of freedom difficulty in the analysis and actions done to address it, such as PCA comes with loss of variation in the original set of variables. Furthermore, the measures created for international experience and psychological characteristics because of low degrees of freedom prevented a deeper analysis of relative significance of dimensions. Future analyses that explore the relative significance of foreign language versus cross-cultural training or non-U.S. national background, or openness versus extraversion, can further shed light into the selection criteria for international assignments.

\section{ACKNOWLEDGMENTS}

The author thanks anonymous referees and the seminar participants at Schumpeter School of Business and Economics in Wuppertal, Germany, particularly Diemo Urbig and Vivien Procher at Jackstadt Center, for their comments and suggestions.

\section{REFERENCES}

Adler, N. J. (1984a). Women do not want international careers: And other myths about international management. Organizational Dynamics, 13(2), 66-79.

Adler, N. J. (1984b). Women in international management: Where are they? California Management Review, 26(4), 78-89.

Adler, N. J. (1986). International dimensions of organizational behavior. Boston, MA: PWS Kent.

Adler, N. J. (1987). Pacific basin managers: A gajin, not a woman. Human Resource Management, 26(2), 169-191.

Apesteguia, J., Azmat, G., \& Iriberri, N. (2012). The impact of gender composition on team performance and decision making: Evidence from the field. Management Science, 58(1), 78-93.

Arce, D., \& Li, S. (2011). Profits, layoffs and priorities. Journal of Business Ethics, 101(1), 49-60.

Arthur, W., \& Bennett, W. (1995). The international assignee: The relative importance of factors perceived to contribute to success. Personnel Psychology, 48(1), 99-114.

Ashforth, B., \& Mael, F. (1989). Social identity and the organization. Academy of Management Review, 14(1), 20-39.

Bandura, A., \& Locke, E. (2003). Negative self-efficacy and goal effects revisited. Journal of Applied Psychology, 88(1), 87-99.

Bhaskar-Shrinivas, P., Harrison, D., Shaffer, M., \& Luk, D. (2005). Inputbased and time-based modes of international adjustment: Metaanalytic evidence and theoretical extensions. Academy of Management Journal, 48, 257-281.

Bjorkmann, I., \& Gersten, M. (1993). Selecting and training Scandinavian expatriates: Determinants of corporate practice. Scandinavian Journal of Management, 9, 145-164.

Black, J. (1990). The relationship of personal characteristics with adjustment of Japanese expatriate managers. Management International Review, 30, 119-134.

Black, J., \& Mendenhall, M. (1990). Cross-cultural training effectiveness: A review and a theoretical framework for future research. Academy of Management Review, 15(1), 113-136.
Black, J., \& Stephens, G. (1989). The influence of the spouse on American expatriate adjustment and intent to stay in Pacific Rim overseas assignments. Journal of Management, 15, 529-544.

Bochner, S., Hutnik, N., \& Furnham, A. (1986). The friendship patterns of overseas students and host students in an Oxford student resident hall. Journal of Social Psychology, 125, 689-694.

Bonache, J., Brewster, C., \& Suutari, V. (2001). Expatriation: A developing research agenda. Thunderbird International Business Review, 43, 3-20.

Brewster, C. (1991). The management of expatriates. London, England: Kogan Page.

Brislin, R. (1981). Cross-cultural encounters: Face-to-face interaction. Elmsford, NY: Pergamon.

Byrne, D. (1971). The attraction paradigm. New York, NY: Academic Press.

Caligiuri, P. (1997). Assessing expatriate success: Beyond just "being there." In Z. Aycan (Ed.), Expatriate management: Theory and practice (pp. 45-67). Greenwich, CT: JAI Press.

Caligiuri, P. (2000). The big five personality characteristics as predictors of expatriate success. Personnel Psychology, 53(1), 67-88.

Caligiuri, P., \& Tarique, I. (2006). International assignee selection and cross-cultural training and development. In I. Bjorkman \& G. Stahl (Eds.), Handbook of research in international human resource management. London, England: Edward Elgar.

Caligiuri, P., Tarique, I., \& Jacobs, R. (2009). Selection for international assignments. Human Resource Management Review, 19(3), 251-262.

Caligiuri, P. M., \& Cascio, W. F. (1998). "Can we send her there?" Maximizing the success of Western women on global assignments. Journal of World Business, 33(4), 394-416.

Chattopadhyay, P., Tluchowska, M., \& George, E. (2004). Identifying the in-group: A closer look at the influence of demographic dissimilarity on employee social identity. Academy of Management Review, 29(2), 180-202.

Chusmir, L. H., \& Frontczak, N. T. (1990). International management opportunities for women: Women and men paint different pictures. International Journal of Management, 7, 295-301.

Collings, D. G., Scullion, H., \& Morley, M. J. (2007). Changing patterns of global staffing in the multinational enterprise: Challenges to the conventional expatriate assignment and emerging alternatives. Journal of World Business, 42, 198-213.

Cui, G., \& Van Den Berg, S. (1991). Testing the construct validity of intercultural effectiveness. International Journal of Intercultural Relations, 15(1), 311-328.

Dienesch, R. M., \& Liden, R. C. (1986). The leader-member exchange model of leadership: A critique and further development. Academy of Management Review, 11, 618-634.

Earley, P., \& Ang, S. (2003). Cultural intelligence: An analysis of individual interactions across cultures. Palo Alto, CA: Stanford University Press.

Egan, M. L., Bendick, M., \& Miller, J. J. (2002). US firms' evaluation of employee credentials in international business. International Journal of Human Resource Management, 13(1), 76-88.

Elsass, P., \& Graves, L. (1997). Demographic diversity in decision-making groups: The experience of women and people of color. Academy of Management Review, 22, 946-973.

Feely, A., \& Harzing, A. (2003). Language management in multi-national companies. Cross Cultural Management, 10(2), 37-52.

Feltes, B., \& Steinhaus, C. (1998). Wanted: International managers women should apply. Business Forum, 23(1), 13-16.

Fiedler, F. (1964). A theory of leadership effectiveness. In L. Berkowitz (Ed.), Advances in Experimental Social Psychology. New York, NY: Academic Press. 149-190.

Friedman, R., Chi, S., \& Liu, L. (2006). An expectancy model of ChineseAmerican differences in conflict-avoiding. Journal of International Business Studies, 37(1), 76-91.

Frontczak, N. T., \& Cateora, P. R. (1988). Opportunities for women in international business: An update. In F. L. Patrone (Ed.), Proceedings for Mountain Plains Management Conference, 71-78.

Gersten, M. C. (1990). Intercultural competence and expatriates. International Journal of Human Resource Management, 1, 341-362.

Ghoshal, S., \& Bartlett, C. (1997). The myth of the generic manager: New resource competencies for management roles. California Management Review, 40, 92-107. 
Global Relocation Trends. (2014). Global relocation trends 2014 survey report. Scottsdale, AZ: Brookfield Global Relocation Services.

Golembiewski, R., Munzenrider, R., \& Stevenson, J. (1986). Stress in organizations: Toward a phase model of burnout. New York, NY: Praeger.

Harris, H., \& Brewster, C. (1999). The coffee-machine system: How international selection really works. International Journal of Human Resource Management, 10, 488-500.

Harvey, M. (1985). The executive family: An overlooked variable in international assignments. Thunderbird International Business Review, 27(3), 15-16.

Harvey, M., Novicevic, M., Buckley, M., \& Fung, H. (2005). Reducing inpatriate managers' "liability of foreignness" by addressing stigmatization and stereotype threats. Journal of World Business, 40, 267-280.

Hui, M., Au, K., \& Fock, H. (2004). Empowerment effects across cultures. Journal of International Business Studies, 35(1), 46-60.

Ibarra, H. (1992). Homophily and differential returns: Sex differences in network structure and access in an advertising firm. Administrative Science Quarterly, 37, 422-447.

loannou, L. (1994). Women's global career ladder. International Business, 20(4), 57-60.

Izraeli, D. N., Banai, M., \& Zeira, Y. (1980). Women executives in MNC subsidiaries. California Management Review, 23(1), 53-63.

Kealey, D. J. (1990). Cross-cultural effectiveness. Hull, Quebec, Canada: SIDA.

Kefales, A. (1998). Think globally, act locally. Thunderbird International Business Review, 40, 547-562.

Lawrence, P., \& Lorsch J. (1967). Organization and environment: Managing differentiation and integration. Boston, MA: Harvard University Press.

Liden, R. C., \& Graen, G. (1980). Generalizability of the vertical dyad linkage model of leadership. Academy of Management Journal, 23, 451-465.

Linehan, M., \& Scullion, H. (2001). Challenges for female international managers: Evidence from Europe. Journal of Managerial Psychology, 16, 215-228.

Mamman, A. (1995). Socio-biographical antecedents of intercultural effectiveness: The neglected factors. British Journal of Management, 6, 97-114.

McEvoy, G., \& Parker, B. (1995). Expatriate adjustment: Causes and consequences. In J. Selmer (Ed.), Expatriate management: New ideas for international business (pp. 97-114). Westport, CT: Quorum Books.

Mendenhall, M., Dunbar, E., \& Oddou, C. (1987). Expatriate selection, training and career pathing: A review and critique. Human Resource Management, 26, 331-345.

Mendenhall, M., Kuhlmann, T., Stahl, G. K., \& Osland, J. (2002). Employee development and expatriate assignments. In M. J. Gannon, \& K. L. Newman (Eds.), The Blackwell handbook of cross-cultural management (pp. 155-184). Malden, MA: Blackwell Business.

Mol, S., Born, M., Willemsen, M., \& Van Der Molen, H. (2005). Predicting expatriate job performance for selection purposes: A quantitative review. Journal of Cross-Cultural Psychology, 36, 590-620.

Morgan, G. (2007). Images of organizations. Thousand Oaks, CA: Sage.

Netemeyer, R., Boles, J., \& McMurrian, R. (1996). Development and validation of work-family conflict and family-work conflict scales. Journal of Applied Psychology, 81, 400-410.

Numerof, R. (1983). Managing stress: A guide for health professionals. Rockville, MD: Aspen Systems.

Paul, H. (2000). Creating a global mindset. Thunderbird International Business Review, 42, 187-200.

Perlman, B., \& Hartman, E. (1982). Burnout: Summary and future research. Human Relations, 35, 283-305.

Reiche, S., \& Harzing, A. W. K. (2009). International assignments. In A. W. K. Harzing (Ed.), International Human Resource Management. London, England: Sage.

Scott, W. R. (1981). Organizations: Rational, natural, and open systems. Englewood Cliffs, NJ: Prentice Hall.

Scullion, H., \& Collings, D. (2006). Global staffing. London, England: Routledge.

Searle, W., \& Ward, C. (1990). The prediction of psychological and sociocultural adjustment during cross-cultural transitions. International Journal of Intercultural Relations, 14, 449-464.
Selmer, J. (2002). To train or not to train? European expatriate managers in China. International Journal of Cross-Cultural Management, 2(1), 3751.

Seltzer, J., \& Numerof, R. (1988). Supervisor leadership and subordinate burnout. Academy of Management Journal, 31, 439-446.

Shaffer, M., \& Harrison, D. (1998). Expatriates' psychological withdrawal from international assignments: Work, nonwork, and family influences. Personnel Psychology, 51, 87-118.

Shaffer, M., Harrison, D., \& Gilley, K. (1999). Dimensions, determinants, and differences in expatriate adjustment process. Journal of International Business Studies, 30, 557-581.

Shaffer, M., Harrison, D., Gregersen, H., Black, J., \& Ferzandi, L. (2006). You can take it with you: Individual differences and expatriate effectiveness. Journal of Applied Psychology, 91, 109-125.

Solomon, C. M. (1998). Women expats: Shattering the myths. Workforce, 3(3), 10-12.

Sparrow, P., Brewster, C., \& Harris, H. (2004). Globalizing human resource management. London, England: Routledge.

Spreitzer, G., McCall, M., \& Mahoney, J. (1997). Early identification of international executive potential. Journal of Applied Psychology, 82(1), 6-29.

Stroh, L. K., \& Caligiuri, P. M. (1998). Strategic human resources: A new source for competitive advantage in the global arena. International Journal of Human Resource Management, 9, 1-17.

Stroh, L. K., Varma, A., \& Valy-Durbin, S. J. (2000). Why are women left at home: Are they unwilling to go on international assignments? Journal of World Business, 35, 241-255.

Takeuchi, R., Tesluk, P., Yun, S., \& Lepak, D. (2005). An integrative view of international experiences: An empirical examination. Academy of Management Journal, 48(1), 85-100.

Taylor, S., \& Napier, N. (1996). Working in Japan: Lessons from women expatriates. Sloan Management Review, 37(3), 76-84.

Thal, N. L., \& Cateora, P. R. (1979). Opportunities for women in international business. Business Horizons, 22(6), 21-27.

Thompson, J. (1967). Organizations in action. New York, NY: McGrawHill.

Tsui, A., \& Gutek, B. (1999). Demographic differences in organizations: Current research and future directions. Lanham, MD: Lexington.

Tung, R. (1981). Selecting and training of personnel for overseas assignments. Columbia Journal of World Business, 16(1), 68-78.

Tung, R. (1993). Managing cross-national and intra-national diversity. Human Resource Management, 32, 461-477.

Tung, R. (1998). American expatriates abroad: From neophytes to cosmopolitans. Journal of World Business, 33, 125-140.

Tung, R. (2008). Do race and gender matter in international assignments to/from Asia Pacific? An exploratory study of attitudes among Chinese. Human Resource Management, 47(1), 91-110.

University of Manchester Institute of Science and Technology (UMIST). (1995). Assessment, selection and preparation for expatriate assignments: Results of a survey of organizational policy and practice. Manchester, England: Manchester School of Management.

Varma, A., Stroh, L., \& Schmitt, L. (2001). Women and international assignments: The impact of supervisor-subordinate relationships. Journal of World Business, 36, 380-388.

Vecchio, R., \& Bullis, R. (2001). Moderators of the influence of supervisor-subordinate similarity on subordinate outcomes. Journal of Applied Psychology, 86(5), 1-13.

Welch, D. E. (1994). HRM implications of globalization. Journal of General Management, 19(4), 52-68.

Welch, D. E., Welch, L. S., \& Worm, V. (2007). The international business traveler: A neglected but strategic human resource. International Journal of Human Resource Management, 18, 173-183.

Welch, D. E., Worm, V., \& Fenwick, M. (2003). Are virtual assignments feasible? Management International Review, 43(1), 95-114.

Westwood, R. I., \& Leung, S. M. (1994). The female expatriate manager experience: Coping with gender and culture. International Studies of Management \& Organizations, 24(3), 64-85.

Yochanan, A., \& Shortland, S. (2001). Women, aliens and international assignments. Women in Management Review, 16(3), 141-145. 


\section{AUTHOR BIOGRAPHY}

Dr. Yener Kandogan is a professor of international business at the School of Management of the University of Michigan-Flint. $\mathrm{He}$ is also a faculty associate at the Center for Russian, East European, and Eurasian Studies of the University of Michigan. His areas of expertise include free trade agreements, international assignment selection, social network analysis of trade, immigration and trade, and role of culture/language on trade. He has about 30 academic publications in various international business and economics journals. He speaks French and is a native of Turkey.yener@umich.edu
How to cite this article: Kandogan Y. What do managers look for in candidates for international assignments? Thunderbird Int Bus Rev. 2018;60:823-835. https://doi.org/10.1002/ tie.21916 